\title{
Incorporating Early Spring Bulbs into Dormant Warm-season Turfgrasses
}

\author{
Michael D. Richardson ${ }^{1,3}$, John McCalla ${ }^{1}$, Tina Buxton ${ }^{1}$, and \\ Filippo Lulli ${ }^{2}$
}

ADDITIONAL INDEX WORDS. preemergence herbicide, mowing, Crocus tommasinianus, Iris reticulata, Galanthus elwesii, Crocus chrysanthus, Zoysia japonica

SuMmARY. Many early spring bulb species are naturally found in grassy areas such as meadows or lawns. However, few studies have been conducted to define this concept in maintained lawns, especially warm-season lawns such as zoysiagrass (Zoysia japonica) or bermudagrass (Cynodon dactylon). Four early spring bulb species, including two crocus species (Crocus tommasinianus 'Ruby Giant' and Crocus chrysanthus 'Goldilocks'), reticulated iris (Iris reticulata 'Cantab'), and snowdrop (Galanthus elwesii) were established in a zoysiagrass lawn site in Fall 2010. In Spring 2011 and 2012, five common preemergence herbicides used on lawns were applied across the plots to determine phytotoxicity. In addition, mowing treatments were started on plots at two timings (15 Mar. and $15 \mathrm{Apr}$.) to determine how mowing might affect survival and performance of the bulb species. Early performance was good for all bulb species and greater than $50 \%$ flower production was observed in the first spring (2011) after planting. However, in the subsequent 3 years (2012-14), the only species that persisted and continued to flower adequately each spring was 'Ruby Giant' crocus. Herbicides and mowing did not affect bulb survival or performance in the trial, suggesting that typical lawn management practices will not be deleterious to the bulbs. These results demonstrate that early spring bulbs may be incorporated into dormant, warm-season lawns, but species and cultivar selection will be crucial for long-term performance.

S pring-flowering bulbs like daffodil (Narcissus sp.), hyacinth (Hyacinthus sp.), and crocus (Crocus sp.) are some of the earliest flowers to appear in gardens each year and are widely planted throughout the world (Armitage, 2008). Many species will bloom for years with minimal care, while others are best planted for one or two seasons of color. Spring bulbs will typically flower from late winter to early summer, depending on species (Dana et al., 2001). After bloom is finished, they continue to photosynthesize and store energy for a period before becoming dormant through summer and into fall (Chrungoo et al., 1983).

All spring bulb species have specific ecological niches that they prefer (Bryan, 2002), but many are found naturally in meadow areas that contain a combination of grasses, other monocots, and dicotyledonous plants. Some species such as crocus and snowdrop are still commonly found naturalized in meadows and mixed species environments (Bryan, 2002;

${ }^{1}$ University of Arkansas, Department of Horticulture, Fayetteville, AR 72701

${ }^{2}$ Turf Europe, Via G. Malasoma, 24-56121 Pisa, Italy

${ }^{3}$ Corresponding author.E-mail: mricha@uark.edu.
Leeds, 2000). Although images of mixed bulb/grass lawns or meadows can be found in texts and on the Internet, a comprehensive literature search did not reveal any studies that examined these combinations in an experimental setting. In addition, most of the examples that could be found were from regions where cool-season grasses such as fescue (Festuca sp.), bentgrass (Agrostis sp.), and bluegrass (Poa sp.) would predominate. There has been renewed interest in mixed-stand lawns that provide color during certain times of the year or potentially fix nitrogen from the atmosphere via the inclusion of species such as white clover (Trifolium repens), yarrow (Achillea millefolium), yellow bedstraw (Galium verum), veronica (Veronica chamaedrys), and english daisy (Bellis perennis) (Cook, 2007;
McCurdy et al., 2013; Rumball, 1989). These efforts confirm the growing interest in using polystands in certain lawn situations to improve the aesthetics and stability of those lawns.

Throughout the transition zone (U.S. Department of Agriculture hardiness zone 6), warm-season turfgrasses such as bermudagrass and zoysiagrass are commonly used in a variety of turf situations, including lawns and landscapes (Burton, 1974; Peterson et al., 2014). Although these grasses are persistent and provide an excellent surface for lawns, they also experience an extended dormancy period from late fall to spring. In the more northern regions of adaptation, this dormancy period can last for up to 6 months, from mid-October through early April (Baldwin et al., 2009; Patton and Reicher, 2007). Since these grasses are predominantly dormant during the period of flowering and growth of early spring bulbs, it was hypothesized that spring bulbs could be incorporated into a dormant lawn so that a show of spring color could be experienced before active growth of the turfgrass was started. For this system to work effectively, it would be desirable for the normal activity of the bulbs to be unaffected by routine cultural practices applied to turfgrass systems during that time, especially as it relates to herbicide applications or mowing.

The overall objective of this study was to examine the flowering capacity and persistence of several early spring bulbs in a zoysiagrass lawn. Zoysiagrass was chosen for this study since it is a very competitive warm-season grass against other plants and weeds (Busey et al., 1982) and would be considered the most difficult environment for bulbs to persist. A second objective was to examine the effects of common preemergence herbicides and mowing practices on the performance of the bulbs.

\begin{tabular}{llll}
\hline $\begin{array}{l}\text { Units } \\
\begin{array}{l}\text { To convert U.S. to SI, } \\
\text { multiply by }\end{array}\end{array}$ & U.S. unit & SI unit & $\begin{array}{l}\text { To convert SI to U.S., } \\
\text { multiply by }\end{array}$ \\
\hline 0.3048 & $\mathrm{ft}$ & $\mathrm{m}$ & 3.2808 \\
9.2903 & $\mathrm{ft}^{2}$ & $\mathrm{dm}^{2}$ & 0.1076 \\
2.54 & inch $(\mathrm{es})$ & $\mathrm{cm}$ & 0.3937 \\
48.8243 & $\mathrm{lb} / 1000 \mathrm{ft}^{2}$ & $\mathrm{~kg} \cdot \mathrm{ha}^{-1}$ & 0.0205 \\
1.1209 & $\mathrm{lb} / \mathrm{acre}$ & $\mathrm{kg} \cdot \mathrm{ha}^{-1}$ & 0.8922
\end{tabular}




\section{Materials and methods}

A field study was established on 15 Nov. 2010 at the University of Arkansas, Agricultural Research and Extension Center in Fayetteville. The soil at the site is a Captina silt loam (fine-silty, siliceous, active, mesic Typic Fragiudults) with an average $\mathrm{pH}$ of 6.2 . The area selected for the study was a full-sun site established in 2007 to 'Zenith' zoysiagrass. Mowing height of the zoysiagrass was 2.0 inches during the active growing season and the turf received $2.0 \mathrm{lb} / 1000$ $\mathrm{ft}^{2}$ nitrogen during the growing season as a slow-release, methylene urea, split between an application in April and July each season. Phosphorous and potassium were not applied during the study as soil test values indicated sufficiency of both elements throughout the study. The site received irrigation during the summer to prevent drought stress on the turf and this generally represented a single irrigation $(\approx 1$ inch) each week during the peak of the summer in the absence of rainfall.

Initially, five early spring bulb species were planted to the site, but one species, glory-of-the-snow ( $\mathrm{Chi}$ onodoxa luciliae), failed to emerge the first year and was not included in data collection and discussion. The other four species, their respective cultivar, and planting density are described in Table 1. All bulb species tested in this trial were obtained from Van Engelen Inc. (Bantam, CT) and selected based on their observed performance in gardens in the region and recommendations from local horticulturists. Before planting, the turfgrass area was cultivated with a hollow-tine cultivator (Toro Co., Bloomington, MN) equipped with $5 / 8$-inch-diameter tines that penetrated the soil to a depth of 4 inches. Cores were removed from the site and bulbs were planted in open holes left by the cultivator at the specified rates. A sandy soil was top-dressed on the plots to a depth of $1 / 4$ inch and then brushed using a shop broom to partially cover the bulbs in the open holes. Plot size for the bulb species was $4 \times 10 \mathrm{ft}$ and each bulb entry was replicated three times in a randomized complete block design.

In Spring 2011 and 2012, two other treatments were applied across the bulb species. The first set of treatments included testing the effects of some common preemergence herbicides that are used on warmseason lawns in the region (Table 2 ). Preemergence herbicides were ap2012, which is the target date for preemergence applications in the region (Patton and Boyd, 2010). Herbicides were randomly applied to $2 \times$ 4 -ft strip plots using either a drop spreader (Gandy Co., Owatonna, $\mathrm{MN}$ ) for the granular herbicides or a carbon dioxide-pressurized sprayer for the liquid treatment. All herbicides were irrigated lightly $(\approx 1 / 4$ inch) immediately after application to move the chemicals to the soil surface. Herbicide injury was monitored for 2 weeks after application but no phytotoxicity was observed in either year or with any of the products. The second treatments were mowing initiation dates and were applied in $2 \times 10$ - $\mathrm{ft}$ strips perpendicular to the herbicide treatments. Mowing treatments included initiation of mowing on either 15 Mar. or 15 Apr. each year and were applied on those dates regardless of how much greenup had occurred in the zoysiagrass turf. The experimental design for the study was a strip, split plot with bulb species as whole plots, herbicides as strips and mowing initiation dates as the split. All treatment combinations were replicated three times.

Data collection for the trial was primarily focused on persistence and performance of the bulbs over plied on I Mar. 2011 and 1 Mar.

a 4-year evaluation period (201114). Each spring, the number of flowers in each plot was visually counted and the data reported as the percentage of bulbs that were planted that produced at least one flower. Since the time of peak flowering varied for each species, data for each species were collected when peak flowering was observed. During the first 2 years of the trial, date of first flower emergence of the various bulb species was also documented.

For the first 2 years of data collection on the trial (2011 and 2012), treatment effects were analyzed according to the strip-split plot model using PROC GLM in SAS (version 9.2; SAS Institute, Cary, NC). However, there were no significant main effects or interactions with herbicides or mowing dates and all data were subsequently analyzed against the main effects of species over the 4 years of the study. Fisher's protected least significant difference test was used at the $P=0.05$ level to identify significant differences among means.

\section{Results and discussion}

Herbicide efFects. The preemergence herbicides tested in this trial caused no visual phytotoxicity to any of the bulb species in either 2011 or 2012 , nor caused any effect on survival or flowering (data not shown). Although there are minimal data on herbicide tolerance of spring bulbs in the landscape setting, there

Table 1. Bulb species, cultivar (if known), and planting density used in a trial to test the performance of early-season bulbs planted in a zoysiagrass lawn.

\begin{tabular}{llc}
\hline Common name & \multicolumn{1}{c}{ Cultivar } & Planting density $\left(\mathrm{bulbs} / \mathrm{ft}^{2}\right)^{\mathbf{z}}$ \\
\hline Crocus & Ruby Giant & 15 \\
Reticulated iris & Cantab & 15 \\
Snowdrop & Cultivar not stated & 10 \\
Crocus & Goldilocks & 15 \\
\hline
\end{tabular}

${ }^{2} 1 \mathrm{bulb} / \mathrm{ft}^{2}=10.7639$ bulbs $/ \mathrm{m}^{2}$.

Table 2. Preemergence herbicides tested across four early-spring bulb species established in a zoysiagrass lawn. All herbicides were applied on 1 Mar. 2011 and 1 Mar. 2012.

\begin{tabular}{llc}
\hline Active ingredient & Formulation & Rate $(\mathbf{l b} / \mathbf{a c r e})^{\mathbf{z}}$ \\
\hline Trifluralin & Granular & 3.0 \\
Prodiamine & Granular & 0.75 \\
Prodiamine & Liquid & 0.75 \\
Pendimethalin & Granular & 3.0 \\
Untreated & &
\end{tabular}

${ }^{2} 1.0 \mathrm{lb} / \mathrm{acre}=1.1209 \mathrm{~kg} \cdot \mathrm{ha}^{-1}$ 
are several research reports published that have shown that many bulb species can adequately tolerate preemergence herbicides in production systems. Al-Khatib (1996) demonstrated that daffodil was tolerant of several key preemergence herbicides in a bulb production setting, including some common preemergence herbicides used on turfgrasses such as pronamide, oryzalin, and dithiopyr. In that same study, daffodil was shown to be sensitive to the herbicides oxadiazon and pendimethalin, but injury from pendimethalin was modest and the use of the herbicide had no effect on bulb size or total bulb dry weight. Smith and Treaster (1984) also reported significant injury from oxadiazon on tulip (Tulipa sp.), daffodil, and crocus, but minimal injury from napropamide, oryzalin, and trifluralin. Norcini and Aldrich (1992) observed minimal injury on daylily (Hemerocallissp.) from granular formulations of dithiopyr, isoxaben, and trifluralin, but some injury from a granular application of oxadizon. In the present study, three of the four herbicides tested were granular formulations, which have been shown to cause less injury to a host of ornamental plants compared with liquid formulations (Glaze et al., 1987). However, neither the granular nor liquid formulations caused phytotoxicity to any of the bulbs tested in this study (data not shown).

Mowing EFFects. Timing to start mowing had no effect on bulb survival or performance in 2011 or 2012 (data not shown). Flower emergence in the tested spring bulbs ranged from 16 Jan. to $27 \mathrm{Feb}$. in 2011 and 2012 (Table 3), so all species generally had between 30 and $60 \mathrm{~d}$ of undisturbed growth after flowering before mowing was started. It has been well documented in bulb species that a period of photosynthetic activity is required after flowering to assimilate new storage carbohydrates in either the bulbs or other underground structures to assure adequate bulb size for the subsequent season or harvest (Benschop and van der Valk, 1984; Kalin, 1954; Wang, 1990). However, we are not aware of any published data on the required length of time before defoliation for any of the species tested in the current trial. One possible reason that mowing did not affect bulb performance in this trial is that the bulb species tested were all lowgrowing (leaf area $<2.5$ inches tall) and, even when mowing was started, a significant portion of leaf area was retained. As such, photosynthetic capacity may not be limited enough to have a significant effect on bulb survival and performance. In a study on tulip production, greater reductions in bulb production were observed when lower leaves were removed compared with upper leaves (Benscop and van der Valk, 1984), suggesting that removal of upper leaves by mowing in these low-growing bulbs may not be detrimental to bulb performance. It would still be recommended that mowing be delayed as long as possible in this system and that mowing height be maintained as tall as possible while bulbs have green leaves present.

Bulb Performance. During the first spring (2011) after planting, all species produced greater than $50 \%$ percentage of planted bulbs that produced blooms varied between flowers, although differences in the

species (Figs. 1 and 2). The snowdrop had the highest percentage of planted bulbs that produced flowers in the first spring, while the 'Goldilocks' crocus had the lowest flower production in 2011. As these trials moved into subsequent years, three of the species, 'Goldilocks' crocus, snowdrop, and reticulated iris, experienced a significant decline in flower production and were producing unsatisfactory results (less than $40 \%$ flower production) in the second year (2012) of the trial (Fig. 1). The one species that continued to have satisfactory performance throughout the 3 years of the trial was 'Ruby Giant' crocus (Figs. I and 3 ), as this species sustained greater than $60 \%$ flower production from 2012 to 2014.

The bulb species evaluated in this trial were chosen based on several criteria, including their adaptation to local gardens, but the most important traits for selecting bulbs for this turfgrass system included early spring flowering and plant height. All of the bulbs tested flowered from mid-January until

Table 3. Date of first flower emergence of various spring bulbs established in a zoysiagrass lawn in Fayetteville, AR over the first 2 years of the trial.

\begin{tabular}{lccc}
\hline & 2011 & 2012 & Average \\
\cline { 2 - 4 } Spring bulb species & \multicolumn{3}{c}{ Date of emergence } \\
\hline Snowdrop & $20 \mathrm{Jan}$. & $19 \mathrm{Jan}$. & $20 \mathrm{Jan}$. \\
'Goldilocks' crocus & $10 \mathrm{Feb}$. & $16 \mathrm{Jan}$. & $29 \mathrm{Jan}$. \\
Reticulated iris & $14 \mathrm{Feb}$. & $9 \mathrm{Feb}$. & $12 \mathrm{Feb}$. \\
'Ruby Giant' crocus & $27 \mathrm{Feb}$. & $13 \mathrm{Feb}$. & $20 \mathrm{Feb}$. \\
\hline
\end{tabular}

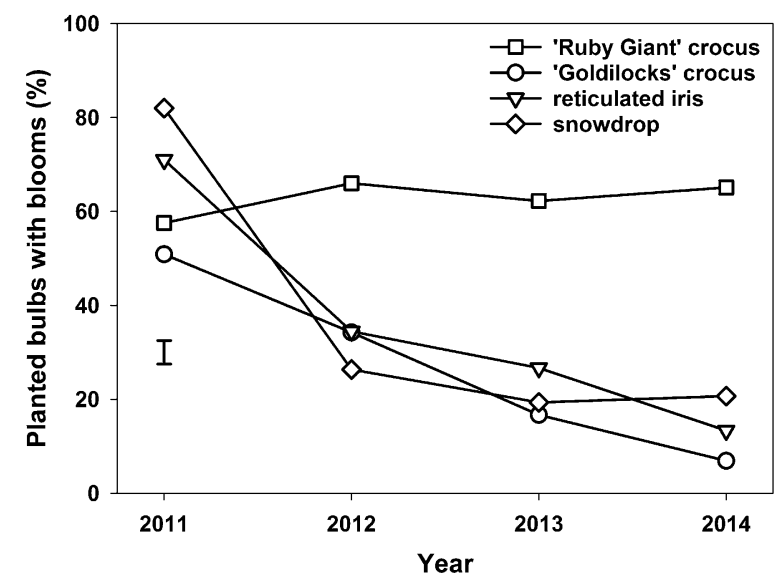

Fig. 1. Year by cultivar interaction for spring bulb performance from 2011 to 2014 when established in a zoysiagrass lawn. Data are presented as the percentage of planted bulbs that produced at least one bloom. Error bar represents the least significant difference $(P=0.05)$ for comparing means. 


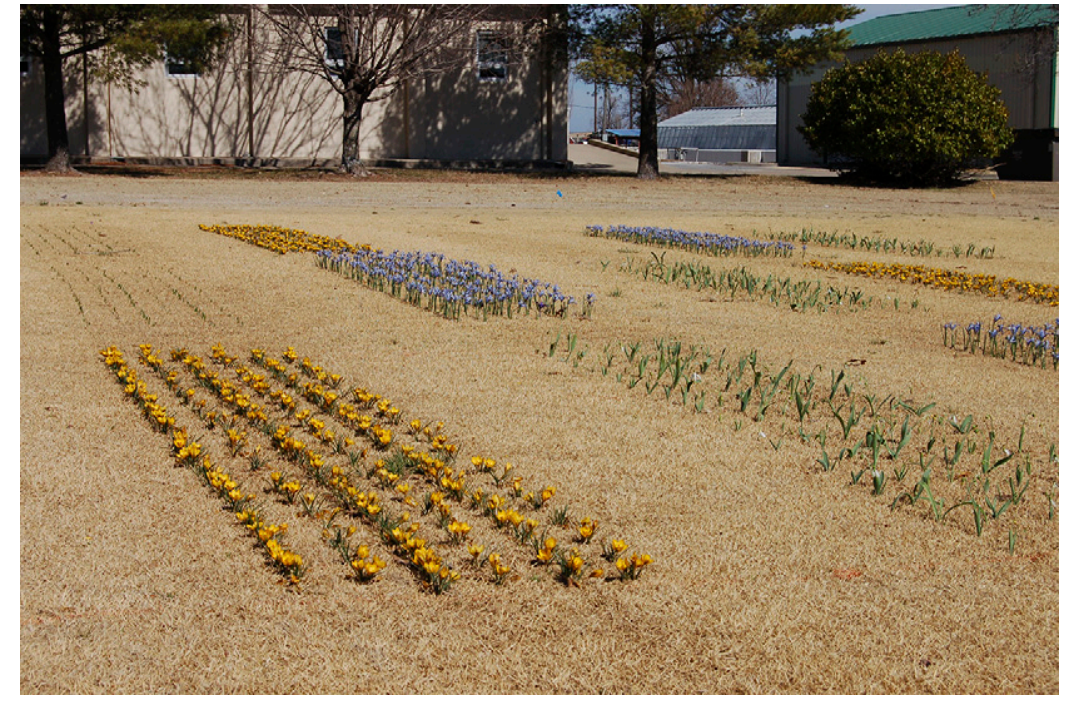

Fig. 2. Overview photograph of the bulb and zoysiagrass plot area during the first spring after establishment (photo taken on 1 Mar. 2011). Plots with yellow flowers in the foreground are 'Goldilocks' crocus and the plots with lavender flowers are reticulated iris.

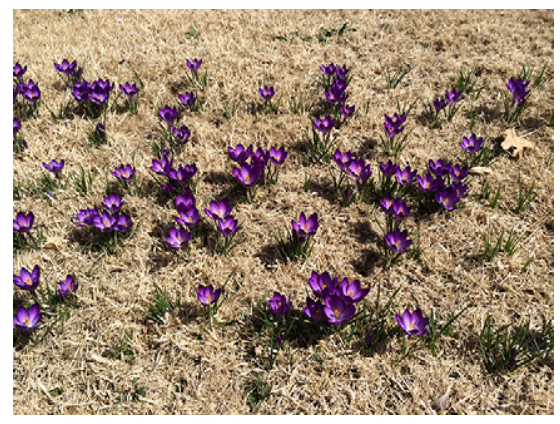

Fig. 3. Photograph of 'Ruby Giant' crocus on 17 Mar. 2014, following 4 years of cultivation in zoysiagrass.

mid-February and were considered appropriate for this particular system, since the date for initial mowing of zoysiagrass in Fayetteville, $\mathrm{AR}$ is typically from early- to mid-April (Patton and Boyd, 2008). It is likely that this system would also work in other warm-season lawn grasses such as bermudagrass because that species also begins growth at a similar time to zoysiagrass. As mentioned previously, zoysiagrass was chosen for this particular study because it is considered the most competitive of the warm-season turfgrasses against other grass species and weeds. It is possible that this competitiveness inhibited some of the bulb species tested in the present trial and those species may work more effectively if incorporated into less competitive warm-season turfgrasses such as bermudagrass, buffalograss
(Buchloe dactyloides), or centipedegrass (Eremochloa ophiuroides).

Several of the tested species, including the two crocus cultivars and snowdrop, have been described in the literature as either commonly found in naturalized meadows or suitable for establishment in lawns (Bryan, 2002; Leeds, 2000), but this is the first report that observed performance of these species in warmseason lawns. Ongoing work in Italy has examined several bulb species, including hairy crocus (Crocus pulchellus), snowdrop (Galanthus nivalis), and tenby daffodil (Narcissus minor), in a bermudagrass lawn setting. Successful bulb establishment with tenby daffodil has been reported from those studies (M. Gaetani, unpublished). While we recognize that the number of species and cultivars tested in the current trial is insufficient to make broad recommendations, this study does establish a proof of concept and suggests that further research is now needed to evaluate a broader group of species and cultivars across a wider geographic region.

\section{Literature cited}

Al-Khatib, K. 1996. Tulip (Tulipa sp.), daffodil (Narcissus sp.) and iris (Iris sp.) response to preemergence herbicides. Weed Technol. 10:710-715.
Armitage, A.M. 2008. Herbaceous perennial plants. Stipes Publishing, Champaign, IL.

Baldwin, C.M., H. Liu, L.B. McCarty, H. Luo, and J.E. Toler. 2009. Dormant bermudagrass spring green-up influenced by shade. Intl. Turf. Soc. Res. J. 11:711721.

Benschop, M. and G.G.M. van der Valk. 1984. The effect of defoliation on bulb production of tulip cultivar 'Apeldoorn'. Sci. Hort. 24:83-91.

Bryan, J.E. 2002. Bulbs. Timber Press, Portland, OR.

Burton, G.W. 1974. Breeding bermudagrass for turf. Intl. Turf. Soc. Res. J. 2: 18-22.

Busey, P., J.A. Reinert, and R.A. Atilano. 1982. Genetic and environmental determinants of zoysiagrass adaptation in a subtropical region. J. Amer. Soc. Hort. Sci. 107:79-82.

Chrungoo, N.K., S. Farooq, and K.K. Koul. 1983. Carbohydrate changes in corms of saffron crocus (Crocus sativus L.) during dormancy and sprouting. Trop. Plant Sci. Res. 1:295-298.

Cook, T. 2007. Ecolawns for the Pacific Northwest. Ore. State Univ., Corvallis. 8 Jan. 2015. <http://horticulture.oregonstate.edu/content/ecolawns-pacificnorthwest>.

Dana, M.N., P. Pecknold, and C. Sadof. 2001. Flowering bulbs. Publication Number HO-86-W. Department of Horticulture, Purdue Univ. Coop. Ext. Serv., West Lafayette, IN.

Glaze, N.C., M. Singh, and S.C. Phatak. 1987. Ornamental response to two methods of oxadiazon application. HortScience 22:265-268.

Kalin, E.W. 1954. Flower removal in the field and its effect on bulb production and forcing quality of Narcissus pseudonarcissus var. King Alfred. Proc. Amer. Soc. Hort. Sci. 63:573-587.

Leeds, R. 2000. The plantfinder's guide to early bulbs. Timber Press, Portland, OR.

McCurdy, J.D., J.S. McElroy, and E.A. Guertal. 2013. White clover (Trifolium repens) establishment within dormant bermudagrass turf: Cultural considerations, establishment timing, seeding rate, and cool-season companion grass species. HortScience 48:15561561 .

Norcini, J.G. and J.H. Aldrich. 1992. Spotted spurge control and phytotoxicity to daylily from preemergence herbicides. J. Environ. Hort. 10:14-17. 


\section{Preliminary and Regional Reports}

Patton, A.J. and J.W. Boyd. 2008. Zoysiagrass lawn calendar. FSA6122-PD-1108RV. Univ. Ark., Div. Agr., Coop. Ext. Serv.

Patton, A.J. and J.W. Boyd. 2010. Turfgrass weed control for professionals. MP370-PD-6-10RV. Univ. Ark., Div. Agr.

Patton, A.J. and Z.J. Reicher. 2007. Zoysiagrass species and genotypes differ in their winter injury and freeze tolerance. Crop Sci. 47:1619-1627.
Peterson, K.W., J.D. Fry, and D.J. Bremer. 2014. Growth responses of Zoysia sp. under tree shade in the midwestern United States. HortScience 49:14441448 .

Rumball, W. 1989. Breeding progress towards wildflower lawns. Intl. Turf. Soc. Res. J 91-93.
Smith, E.M. and S.A. Treaster. 1984. Tolerance of tulip, daffodil, and crocus to selected preemergence herbicides. Ohio St. Univ. Res. Circ. 279:14-15.

Wang, Y.T. 1990. Growth and leaf photosynthesis of Lilium longiflorum Thumb. 'Nellie White' in response to partial defoliation after anthesis. Acta Hort. 266:197-204. 